\title{
Usefulness of the cytokines expression of Th1/Th2/Th17 and urinary CD80 excretion in adult-onset minimal change disease
}

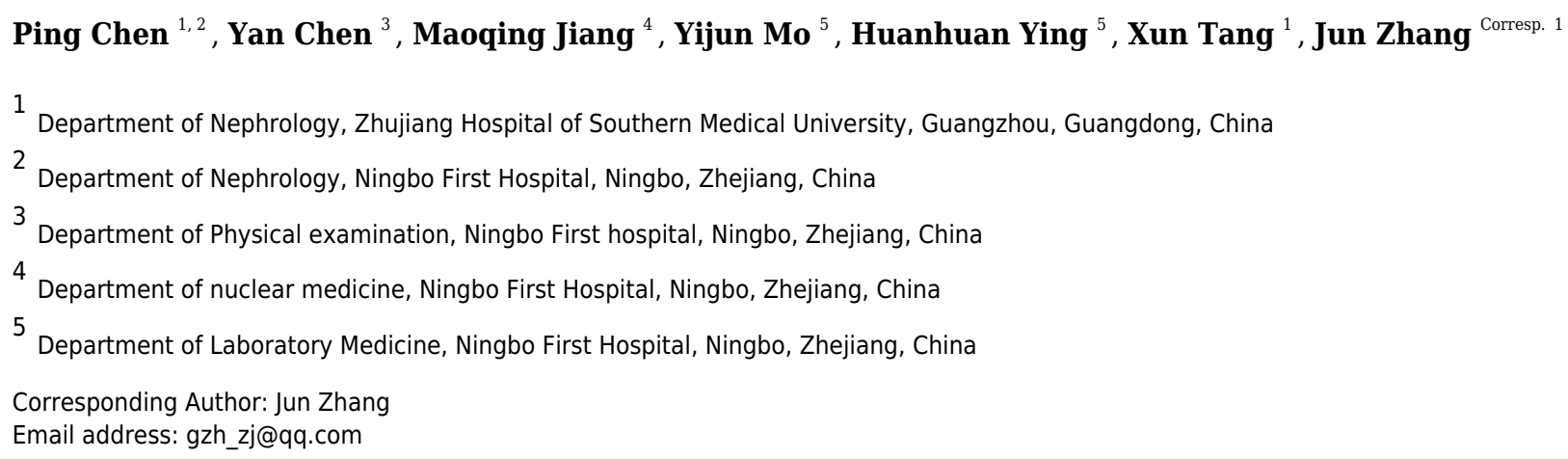

Background : Minimal change disease (MCD) is a common form of nephrotic syndrome in adults. However, the molecular mechanism underlying the pathogenesis of MCD remains incompletely understood. In this study we aimed to investigate the role of the cytokines expression of Th1/Th2/Th17 and urinary CD80 excretion in adult-onset MCD patients.

Methods: The lymphocyte subsets, 34 cytokine levels of Th1/Th2/Th17, serum and urine concentrations of CD80, and expression of CD80 in glomeruli were analyzed in 28 cases (15 males and 13 females; average age: 34.1 years, age range: 18-56 years), including 10 patients with MCD in relapse, 9 patients with MCD in remission and 9 healthy controls.

Results: There was no significant difference of $\mathrm{CD}^{+}{ }^{+} \mathrm{CD} 4{ }^{+}$cells proportion among patients with $\mathrm{MCD}$ in relapse, $M C D$ in remission and healthy controls $(P=0.802)$. The cytokine levels of GM-CSF and tumor necrosis factor (TNF)-related activation-induced cytokine (TRANCE) in patients with MCD in relapse increased 1.5 times higher than those in remission. An evident increase in the excretion of urinary CD80 was found in patients with relapsed MCD compared with those in remission (598.4 115.8 vs $81.78 \pm 7.04$ $\mathrm{ng} / \mathrm{g}$ creatinine, $\mathrm{P}<0.001$ ) and healthy controls $(598.4 \pm 115.8$ vs $67.44 \pm 8.94 \mathrm{ng} / \mathrm{g}$ creatinine, $\mathrm{P}<0.001)$. CD80 expression was observed in podocyte of MCD patient in relapse by immunofluorescence technique.

Conclusions: The cytokines GM-CSF and TRANCE are increased and the urinary CD80 levels are elevated in adult-onset MCD patients in relapse, indicating a disorder of Th1/Th2/Th17 balance and that the elevated excretion of CD80 may underlie the pathogenesis and development of adult-onset MCD. 


\section{Usefulness of the cytokines expression of Th1/Th2/Th17 and urinary}

2 CD80 excretion in adult-onset minimal change disease

3

4 Ping Chen ${ }^{1,2}$, Yan Chen ${ }^{3}$, Maoqing Jiang ${ }^{4}$, Yijun Mo ${ }^{5}$, Huanhuan Ying ${ }^{5}$, Xun Tang ${ }^{1}$, Jun Zhang ${ }^{1}$ 5

6

7 8

Corresponding Author:

Jun Zhang ${ }^{1}$

No. 253, Middle Industrial Avenue, Guangzhou, Guangdong, 510280, China.

Email address: gzh_zj@qq.com

\section{Abstract}

Background: Minimal change disease (MCD) is a common form of nephrotic syndrome in adults. However, the molecular mechanism underlying the pathogenesis of MCD remains incompletely understood. In this study we aimed to investigate the role of the cytokines expression of Th1/Th2/Th17 and urinary CD80 excretion in adult-onset MCD patients.

Methods: The lymphocyte subsets, 34 cytokine levels of Th1/Th2/Th17, serum and urine concentrations of CD80, and expression of CD80 in glomeruli were analyzed in 28 cases (15 males and 13 females; average age: 34.1 years, age range: 18-56 years), including 10 patients with MCD in relapse, 9 patients with MCD in remission and 9 healthy controls.

Results: There was no significant difference of $\mathrm{CD}^{+}{ }^{+} \mathrm{CD} 4{ }^{+}$cells proportion among patients with MCD in relapse, MCD in remission and healthy controls $(P=0.802)$. The cytokine levels of GMCSF and tumor necrosis factor (TNF)-related activation-induced cytokine (TRANCE) in patients 
32 with MCD in relapse increased 1.5 times higher than those in remission. An evident increase in

33 the excretion of urinary CD80 was found in patients with relapsed MCD compared with those in 34 remission $(598.4 \pm 115.8$ vs $81.78 \pm 7.04 \mathrm{ng} / \mathrm{g}$ creatinine, $\mathrm{P}<0.001)$ and healthy controls 35 (598.4 \pm 115.8 vs $67.44 \pm 8.94 \mathrm{ng} / \mathrm{g}$ creatinine, $\mathrm{P}<0.001)$. CD80 expression was observed in 36 podocyte of MCD patient in relapse by immunofluorescence technique.

37 Conclusions: The cytokines GM-CSF and TRANCE are increased and the urinary CD80 levels 38 are elevated in adult-onset MCD patients in relapse, indicating a disorder of Th1/Th2/Th17 39 balance and that the elevated excretion of CD80 may underlie the pathogenesis and development 40 of adult-onset MCD.

41

42

43

44 45

46

47

48

49

50

51

52

53

54

55

56

57

58

59

60

61

62

\section{Introduction}

Minimal change disease (MCD) is commonly regarded as due to $\mathrm{T}$ cell subsets disorder and certain circulating cytokines that trigger dysfunction of podocytes and resulting in proteinuria (Boumediene et al., 2018; Kaneko et al., 2015; Iwabuchi et al., 2018; Wang \& Greenbaum, 2019). However, not much is known about which type of $\mathrm{T}$ cell subset and cytokine play a critical role in the pathogenesis of MCD. Previous studies revealed that patients with MCD were characterized by downregulation of Th1 cytokines and predominance of Th2 and Th17, which might be harmful factors of glomerulus, leading to the occurrence and development of MCD (Le Berre et al., 2005; Salcido-Ochoa et al., 2017). But (Kaneko et al., 2002) reported that the percentages of Th1, Th2 and the ratio of Th1/Th2 showed no significant differences between nephrotic relapse, remission and healthy controls in childhood. Thus, the cytokines expression of Th1/Th2/Th17 still needs to be characterized and evaluated in MCD patients.

CD80, also known as B7-1, is a costimulatory molecule of T cells and is also involved in T cell activation and termination (Novelli, Benigni \& Remuzzi, 2018). (Reiser et al., 2004) demonstrated that induction of CD80 expression on podocyte led to reorganization of actin cytoskeleton that modified glomerular permselectivity and caused proteinuria in mice. Moreover, it has been proposed that MCD is a "two-hit" podocyte immune disorder ((Shimada et al., 2011). The first hit is the induction of CD80 in podocyte by various stimuli and the second hit is the ineffective censoring of podocyte CD80 due to a defective autoregulation by podocyte itself. Besides, urinary CD80 is elevated in MCD in children and measuring urinary CD80 
63 concentrations could distinguish MCD from focal segmental glomerulosclerosis (FSGS) (Ling et 64 al., 2015; Garin et al., 2010; Garin et al., 2009). Recently, a CD80 inhibitor, abatacept (cytotoxic 65 T-lymphocyte-associated antigen 4-immunoglobulin fusion protein, CTLA-4-Ig), was used as a 66 therapeutic drug in "CD80-positive kidney disease" in MCD patients even though in only a 67 limited number of cases (Garin et al., 2015). However, few studies have tried to explain the

74 75 76 77 78 79 80 81 82 83 84 85 86 87 possible reasons why elevated urinary levels of CD80 excretion are encountered in adult-onset MCD.

Therefore, in this study, we aimed to characterize the serum cytokines expression of Th1/Th2/Th17 and urinary CD80 excretion in adult-onset patients with MCD and healthy controls, as well as their role in the pathogenesis and development of MCD.

\section{Materials \& Methods}

\section{Patient selection}

Adult patients with biopsy proven MCD and healthy volunteers were studied (Table 1). None of the healthy control subjects involved in the study had any underlying immunologic disease in the study. Patients with renal dysfunction were excluded (glomerular filtration rate $<60 \mathrm{ml} / \mathrm{min}$ or serum creatinine $>1.5 \mathrm{mg} / \mathrm{dl})$. MCD was defined according to the established pathology criteria (Vivarelli et al., 2017). Relapse of MCD was defined as proteinuria $(\geq 3+$ using the tetrabromophenol-citrate buffer colorimetric qualitative dipstick test or urinary protein/creatinine ratio $>3.0 \mathrm{mg} / \mathrm{mg}$ ), edema and hypoalbuminemia (of $<30 \mathrm{~g} / \mathrm{l}$ ). Remission of MCD was defined as a urinary protein/creatinine ratio $<0.3 \mathrm{mg} / \mathrm{mg}$ or no proteinuria using the colorimetric qualitative test. Our study was approved by the Medical Ethics Committee of Ningbo First Hospital (No. 2017-R033). A written informed consent was obtained from all participants.

\section{Clinical Samples Collection and Cytokine antibody array measure}

We randomly selected six patients with MCD in relapse, three patients with MCD in remission and three healthy controls. From January 2017 to January 2018, 10ml peripheral blood samples were collected from patients with MCD and healthy controls in Ningbo First Hospital, Medical College of Ningbo University. The total 34 cytokines of Th1/Th2/Th17 in MCD patients and healthy controls were detected by cytokine antibody array using a RayBio ${ }^{\circledR}$ human cytokine 
94 antibody array (RayBiotech, Inc, Norcross, GA, USA, and AAH-TH17-G1). Membranes were 95 incubated with diluted antibodies at room temperature for $2 \mathrm{~h}$. The detections were accomplished according to the manufacturer's manual and previous research (Huang, 2001).

\section{Lymphocyte subsets assessment}

We used flow cytometry analysis to detect lymphocyte subsets in whole peripheral blood in ten patients with MCD in relapse, nine patients with MCD in remission and nine healthy controls. Briefly, peripheral blood was incubated with marked monoclonal antibodies for 20 minutes at room temperature in the dark. Then lysing reagent was added and incubated for 15 minutes at room temperature in the dark. The lymphocyte subsets analysis was performed by using a BD flow cytometer (BD Bioscience).

\section{CD80 and CTLA-4 measurements}

A commercially available ELISA kit (Bender Med-Systems, Burlingame, CA, USA) was used for measuring CD80 in blood and urine. We detected CTLA-4 in blood and urine according to previous study (Oaks \& Hallett, 2000). We adjusted the results of CD80 and CTLA-4 with urinary creatinine excretion. Urinary creatinine and protein and serum albumin were detected by an auto-analyzer.

\section{Immunohistochemistry}

We used immunofluorescence technique to test the expression of CD80 in glomeruli of MCD patient in relapse. Snap-frozen renal specimens were incubated with monoclonal synaptopodin or WT-1 antibody (1:50; Santa Cruz, CA) for $2 \mathrm{~h}$ at room temperature to reveal podocyte. Then, we washed the sections three times with PBS and incubated specimens with anti-CD80 antibody (1:100) (goat; R\&D Systems, Minneapolis, MN) $2 \mathrm{~h}$ at room temperature. After washing three times with PBS, we incubated sections with anti-goat 488 and chicken anti-mouse 594 Alexa Fluor antibodies (1:1500, Invitrogen, Carlsbad, CA) for $1 \mathrm{~h}$ at room temperature.

\section{Statistical analysis}


124 Graph Pad Instat version 5.0 was used to perform statistical analysis and data graphics. Non-

125

126

127

128

129

130

131

132

133

134

135

136

137

138

139

140

141

142

143

144

145

146

147

148

149

150

151

152

153

154 parametric ANOVA (Kruskal-Wallis test) was conducted for statistical analysis. We used MannWhitney $U$ test or Wilcoxon signed rank test (when applicable) to determine the differences between means. Spearman correlation coefficient was used to calculate the correlation between urinary CD80 and proteinuria. Values were expressed as means \pm standard error of mean (SEM). Results were considered statistically significant if $P<0.05$.

\section{Results}

\section{Clinical characteristics}

The clinical characteristics and laboratory results of patients with MCD in relapse $(n=10), M C D$ in remission $(n=9)$ and healthy controls $(n=9)$ are summarized in Table 1. A total of 28 cases were reported, 15 males and 13 females, with an average age of $34.1 \pm 2.1$ years (age range: 18 56 years). Patients with MCD in relapse were analyzed at onset of illness. Eight of the relapsed patients were on a tapering dose of immunosuppressive treatment while the remaining two were after drug withdrawal. All patients with MCD in remission were getting immunosuppressive treatment at the time of measuring.

\section{Lymphocyte subsets in the peripheral blood of MCD patients and healthy controls}

We analyzed lymphocyte subsets, including $\mathrm{CD}^{+} \mathrm{T}$ cells, $\mathrm{CD}^{+} \mathrm{CD}^{+} \mathrm{T}$ cells, $\mathrm{CD} 3{ }^{+} \mathrm{CD} 8^{+} \mathrm{T}$ cells, CD3-CD19 ${ }^{+} \mathrm{B}$ cells and $\mathrm{CD} 3{ }^{-} \mathrm{CD} 16^{+} / \mathrm{CD}^{-} 6^{+} \mathrm{NK}$ cells. The distribution of lymphocyte subsets in the peripheral blood of MCD patients and healthy controls are showed in Table 2. There were no statistically significant differences in the proportions of $\mathrm{CD}^{+}$and $\mathrm{CD} 3^{+} \mathrm{CD} 4^{+}$ cells among patients with MCD in relapse, MCD in remission and healthy controls $(P=0.445$ and $P=0.802$ ). $\mathrm{MCD}$ patients in relapse had significant higher proportions of $\mathrm{CD}^{+} \mathrm{CD}^{+}$cells compared to $\mathrm{MCD}$ in remission $(42.7 \pm 2.29 \%$ vs. $27.42 \pm 1.51 \%, P=0.008)$ and healthy controls (42.7 $\pm 2.29 \%$ vs. $27.97 \pm 2.34 \%, P<0.001)$. Furthermore, $\mathrm{CD}^{+} / \mathrm{CD}^{+}$ratio was lower in $\mathrm{MCD}$ in relapse compared with $\mathrm{MCD}$ in remission $(0.84 \pm 0.09$ vs. $1.45 \pm 0.14, P=0.014)$ and healthy controls $(0.84 \pm 0.09$ vs. $1.4 \pm 0.12, P=0.005)$. The $\mathrm{CD}^{-}{ }^{-} \mathrm{CD} 16^{+} / \mathrm{CD}^{2} 6^{+} \mathrm{NK}$ cell and $\mathrm{CD} 3{ }^{-} \mathrm{CD} 19^{+} \mathrm{B}$ cell populations revealed no significant differences among patients with MCD in relapse, MCD in remission and healthy controls $(P=0.199$ and $P=0.445)$. 


\section{Cytokine profiles in serum of MCD patients and controls}

157 We investigated Th1/Th2/Th17 cytokines in the serum of the randomly selected MCD patients 158 and controls by cytokine antibody array (Fig. 1A-1C and Table 3). The characteristics of the 159 randomly selected MCD patients and healthy controls are presented in Table 4. Each cytokine 160 antibody array included 34 cytokines (Fig. 1D). The concentrations that increased by $\geq 1.5$-fold 161 or decreased by $\leq 0.65$-fold were considered as significant. Our results in Table 3 indicate that the 162 levels of GM-CSF and tumor necrosis factor (TNF)-related activation-induced cytokine 163 (TRANCE) in patients with MCD in relapse increased 1.5 times higher than in patients in 164 remission. GM-CSF, IL-10, IL-22 and TNF beta levels increased significantly in patients with $165 \mathrm{MCD}$ in relapse compared to healthy controls. The expression of CD40 was found to have 166 decreased in MCD in relapse compared to healthy controls.

167

\section{Measurement of CD80 and CTLA-4 expression}

169 We explored urinary CD80 expression adjusted by urinary creatinine in patients with MCD in 170 relapse $(n=10)$, MCD in remission $(n=9)$ and healthy controls $(n=9)$ (Fig. 2A). A significant 171 increase in the excretion of urinary CD80 was observed in MCD patients in relapse when 172 compared with patients in remission $(598.4 \pm 115.8 \mathrm{ng} / \mathrm{g}$ vs. $81.78 \pm 7.04 \mathrm{ng} / \mathrm{g}$ creatinine,$P<0.001)$ 173 and healthy controls $(598.4 \pm 115.8 \mathrm{ng} / \mathrm{g}$ vs. $67.44 \pm 8.94 \mathrm{ng} / \mathrm{g}$ creatinine, $P<0.001)$. The excretion 174 of urinary CD80 showed no significant difference between MCD patients in remission and 175 healthy controls $(P=0.269$, Fig. 2A). There was no correlation between urinary CD80 and 176 proteinuria in MCD patients in relapse ( $\mathrm{r}=-0.32, P=0.366$, Fig. 2B).

177 In contrast to the urinary results, no significant differences were found in serum CD80 178 concentrations among patients with MCD in relapse, MCD in remission, and healthy control 179 subjects (379.9 \pm 32.3 vs. $287.6 \pm 19.48$ vs. $342.4 \pm 28.43 \mathrm{pg} / \mathrm{ml}, P=0.081)$. Urinary CTLA-4 levels 180 were not significantly increased in MCD patients in relapse when compared with patients in 181 remission $(173.7 \pm 8.73$ vs. $155.0 \pm 8.54 \mathrm{ng} / \mathrm{g}$ creatinine, $P=0.098)$ and healthy control subjects 182 (173.7 \pm 8.73 vs. $160.0 \pm 10.85 \mathrm{ng} / \mathrm{g}$ creatinine, $P=0.253$, Fig. 2C). There was no correlation 183 between the concentrations of urinary CTLA-4 and proteinuria in MCD patients in relapse 184 (r=0.18, $P=0.632$, Fig. 2D). There was also no inverse correlation between urinary CTLA-4 and 
185 urinary $\mathrm{CD} 80$ in MCD patients in relapse $(\mathrm{r}=0.15, P=0.682$, Fig. 2E) nor in remission $(\mathrm{r}=0.3$, $186 P=0.437$, Fig. 2F).

187 Compared with MCD patients in remission, the urinary CD80 to CTLA-4 ratio was elevated 188 significantly in $\mathrm{MCD}$ in relapse $(P=0.004$, Fig. 3A). No significant differences of serum 189 CD80/CTLA-4 ratio ( $P=0.278$, Fig. 3B) and CTLA-4 concentrations $(P=0.949$, Fig. 3C) were 190 found among patients with MCD in relapse, MCD in remission and healthy controls.

191

The expression of CD80 in podocyte in patient with relapsed MCD

193

We used immunofluorescence technique to test the expression of CD80 in glomeruli of patient 5 as listed in Table 1. Two glomeruli from patient 5 with relapsed MCD were stained for CD80 in green (Fig. 4A and 4D), synaptopodin in red (Fig. 4B) and WT-1 in red (Fig. 4E). The double immunostaining for CD80 and synaptopodin in the glomerulus of MCD patient in relapse showed colocalization (Fig. 4C). CD80 and WT-1 co-localized in the glomerulus of MCD patient in relapse (Fig. 4F).

199

200

201

\section{Discussion}

202

In the present study, we investigated the lymphocyte subsets, 34 cytokines expression of 203 Th1/Th2/Th17 and the CD80 expression in adult-onset MCD. Our results showed that there was 204 no significant difference in the proportion of $\mathrm{CD}^{+}{ }^{+} \mathrm{CD} 4^{+}$cells among patients with $\mathrm{MCD}$ in 205 relapse, MCD in remission and healthy controls, but the cytokines GM-CSF and TNFSF11 were 206 increased and the urinary CD80 levels were elevated in adult-onset MCD patients in relapse, indicating a disorder of $\mathrm{Th} 1 / \mathrm{Th} 2 / \mathrm{Th} 17$ balance and that the elevated excretion of CD80 may underlie the pathogenesis and development of adult-onset MCD.

Even though the proportion of $\mathrm{CD}^{+} \mathrm{CD}^{+}$cells showed no significant difference between patients with MCD and healthy controls, the cytokines of GM-CSF and TRANCE increased 211 significantly in patients with MCD in relapse, which might be due to the changes in $\mathrm{CD}^{+} \mathrm{CD}^{+}$ 212 cell function. Interestingly, we found the proportions of $\mathrm{CD} 8^{+}$counts were elevated in $\mathrm{MCD}$ in 213 relapse compared with controls, implicating CD8 $+\mathrm{T}$ cells might also participate in the course of 214 MCD. GM-CSF, a representative cytokine of Th1 and Th17, is increased in the urine of patients 215 with FSGS and is related to glomerulosclerosis (Stangou et al., 2017). Moreover, GM-CSF is 
216 secreted by renal parenchymal cells and inflammatory cells, which could mediate crescent 217 formation, renal tubule injure and proteinuria, and ultimately lead to renal dysfunction in murine 218 crescentic nephritis (Timoshanko et al., 2005). TRANCE, also known as RANKL, is a cytokine 219 secreted by Th1 and its expression can be promoted by IL-17 which is a cytokine secreted by 220 Th17 (Hienz, Paliwal \& Ivanovski, 2015). However, the role of GM-CSF and TRANCE in 221 patients with MCD is rarely reported. By analyzing the 34 cytokines secreted by Th1/Th2/Th17, 222 we found that GM-CSF and TRANCE in the serum of patients with MCD in relapse were 223 significantly higher than that in patients in remission. To our knowledge, we did not find the 224 same results that there was increased expression of GM-CSF and TRANCE in the serum of

225 226 227 228 229 230 231 232 233 234 235 236 237 238 patients with recurrent MCD. Accordingly, we speculate that the imbalance of Th1/Th2/Th17 in patients with MCD in relapse leads to the increase of GM-CSF and TRANCE secretion by Th1 and Th17 cells, which further induces podocyte damage and leads to proteinuria.

It has been proposed that CD80 plays a vital role in the "two-hit" podocyte immune disorder of MCD (Shimada, Araya, Rivard, Ishimoto, Johnson \& Garin, 2011). Our study showed that the excretion of urinary CD80 increased in adult-onset MCD patients in relapse when compared with MCD in remission and healthy controls. Similar results have been reported in other studies of childhood and adult-onset MCD patients (Garin, Diaz, Mu, Wasserfall, Araya, Segal \& Johnson, 2009; Zhao et al., 2018). However, we found there was no correlation between urinary CD80 and proteinuria in adult-onset MCD patients in relapse, demonstrating the elevated CD80 was not simply a reflection of proteinuria. Besides, the serum CD80 in patients with MCD in remission was not different from those in relapse, implicating that the elevated urinary levels could not be explained by higher serum concentrations. Synaptopodin is a highly expressed actin binding protein in podocyte (Yu et al., 2018). WT-1 is known to be expressed on podocyte in kidney (Funk et al., 2016). The double immunostaining for CD80 and synaptopodin, and CD80 and WT-1 in the glomerulus of MCD patient in relapse showed colocalization, confirming the source of the urinary CD80 in MCD patients in relapse was the podocyte. In general, CD80 cannot be expressed on podocytes, but in some glomerulopathies, its expression on the surface of podocyte is increased. One of the possible reasons is that podocytes are switched to an antigen presenting cell phenotype (Trimarchi, 2015). Although the staining in Fig. 4 was convincing, immunohistochemistry was only performed on a single biopsy and further studies are needed to verify these findings. 
Moreover, CD80 may interact with CTLA-4, which plays a crucial role in cellular and 248 humoral immunity (Greenwald, Freeman \& Sharpe, 2005). We found that urinary or serum 249 CTLA-4 levels were not significantly increased in MCD patients in relapse compared with those 250 in remission. However, the urinary CD80 to CTLA-4 ratio was higher in MCD in relapse versus 251 in remission, which could be due to the defective response of Treg from patients in relapse to 252 produce CTLA-4. (Garin, Reiser, Cara-Fuentes, Wei, Matar, Wang, Alachkar \& Johnson, 2015) 253 reported that abatacept was useful in the treatment of one patient with MCD, but not in FSGS. 254 Thus, the CD80-CTLA-4 axis seems to play an important part in the mechanism of proteinuria in 255 recurrent MCD. Drugs targeting the CD80-CTLA-4 axis may be expected to treat MCD in 256 relapse in the future.

257

There are some limitations in our study. Firstly, the sample size is small, so more studies are 258 needed to verify the expression of GM-CSF and TRANCE in patients with MCD in relapse. Secondly, further studies are needed to explore the mechanism of GM-CSF and TRANCE in 260 podocyte injury of patients with MCD. Thirdly, the interaction between GM-CSF, TRANCE and 261 CD80 pathway in podocyte injury needs to be elucidated.

262

263

\section{Conclusions}

264

In our study, the cytokines GM-CSF and TRANCE were increased in the serum and the urinary 265 CD80 levels were elevated in adult-onset MCD, indicating a disorder of Th1/Th2/Th17 balance 266 and that the elevated excretion of CD80 may underlie the pathogenesis and development of 267 adult-onset MCD. Further studies are warranted to investigate the precise mechanism of the 268 interaction between Th1/Th2/Th17 balance and CD80 during the course of MCD.

269

270

\section{Acknowledgements}

272 This study was supported by the project of medical and health technology program in Zhejiang 273 province (grant no. 2018KY679) and Ningbo medical science and technology program (grant no. 274 2019Y08).

275

276

277

\section{References}


Boumediene A, Vachin P, Sendeyo K, Oniszczuk J, Zhang SY, Henique C, Pawlak A, Audard V, Ollero M, Guigonis V, Sahali D. 2018. NEPHRUTIX: A randomized, double-blind, placebo vs Rituximab-controlled trial assessing T-cell subset changes in Minimal Change Nephrotic Syndrome. J Autoimmun 88:91-102 doi 10.1016/j.jaut.2017.10.006

Kaneko K, Tsuji S, Kimata T, Kitao T, Yamanouchi S, Kato S. 2015. Pathogenesis of childhood idiopathic nephrotic syndrome: a paradigm shift from T-cells to podocytes. World J Pediatr 11 (1):21-28 doi 10.1007/s12519-015-0003-9

Iwabuchi Y, Miyabe Y, Makabe S, Nakano M, Manabe S, Karasawa K, Moriyama T, Nitta K. 2018. Comparison of the response of frequently relapsing steroid-dependent minimal change nephrotic syndrome to rituximab therapy between childhood-onset and adult-onset disease. Medicine (Baltimore) 97 (42):e12704 doi 10.1097/MD.0000000000012704

Wang CS, Greenbaum LA. 2019. Nephrotic Syndrome. Pediatr Clin North Am 66 (1):73-85 doi 10.1016/j.pcl.2018.08.006

Le Berre L, Herve C, Buzelin F, Usal C, Soulillou JP, Dantal J. 2005. Renal macrophage activation and Th2 polarization precedes the development of nephrotic syndrome in Buffalo/Mna rats. Kidney Int 68 (5):20792090 doi 10.1111/j.1523-1755.2005.00664.x

Salcido-Ochoa F, Hue SS, Haase D, Choo JCJ, Yusof N, Li RL, Allen JC, Jr., Iqbal J, Loh AHL, Rotzschke O. 2017. Analysis of T Cell Subsets in Adult Primary/Idiopathic Minimal Change Disease: A Pilot Study. Int $J$ Nephrol 2017:3095425 doi 10.1155/2017/3095425

Kaneko K, Tuchiya K, Fujinaga S, Kawamura R, Ohtomo Y, Shimizu T, Yamashiro Y. 2002. Th1/Th2 balance in childhood idiopathic nephrotic syndrome. Clin Nephrol 58 (6):393-397 doi 10.5414/cnp58393

Novelli R, Benigni A, Remuzzi G. 2018. The role of B7-1 in proteinuria of glomerular origin. Nat Rev Nephrol 14 (9):589-596 doi 10.1038/s41581-018-0037-z

Reiser J, von Gersdorff G, Loos M, Oh J, Asanuma K, Giardino L, Rastaldi MP, Calvaresi N, Watanabe H, Schwarz K, Faul C, Kretzler M, Davidson A, Sugimoto H, Kalluri R, Sharpe AH, Kreidberg JA, Mundel P. 2004. Induction of B7-1 in podocytes is associated with nephrotic syndrome. J Clin Invest 113 (10):1390-1397 doi 10.1172/JCI20402

Shimada M, Araya C, Rivard C, Ishimoto T, Johnson RJ, Garin EH. 2011. Minimal change disease: a "two-hit" podocyte immune disorder? Pediatr Nephrol 26 (4):645-649 doi 10.1007/s00467-010-1676-x

Ling C, Liu X, Shen Y, Chen Z, Fan J, Jiang Y, Meng Q. 2015. Urinary CD80 levels as a diagnostic biomarker of minimal change disease. Pediatr Nephrol 30 (2):309-316 doi 10.1007/s00467-014-2915-3

Garin EH, Mu W, Arthur JM, Rivard CJ, Araya CE, Shimada M, Johnson RJ. 2010. Urinary CD80 is elevated in minimal change disease but not in focal segmental glomerulosclerosis. Kidney Int 78 (3):296-302 doi 10.1038/ki.2010.143

Garin EH, Diaz LN, Mu W, Wasserfall C, Araya C, Segal M, Johnson RJ. 2009. Urinary CD80 excretion increases in idiopathic minimal-change disease. $J$ Am Soc Nephrol 20 (2):260-266 doi 10.1681/ASN.2007080836

Garin EH, Reiser J, Cara-Fuentes G, Wei C, Matar D, Wang H, Alachkar N, Johnson RJ. 2015. Case series: CTLA4-IgG1 therapy in minimal change disease and focal segmental glomerulosclerosis. Pediatr Nephrol 30 (3):469-477 doi 10.1007/s00467-014-2957-6

Vivarelli M, Massella L, Ruggiero B, Emma F. 2017. Minimal Change Disease. Clin J Am Soc Nephrol 12 (2):332-345 doi 10.2215/CJN.05000516

Huang RP. 2001. Detection of multiple proteins in an antibody-based protein microarray system. $J$ Immunol Methods 255 (1-2):1-13 doi 10.1016/s0022-1759(01)00394-5

Oaks MK, Hallett KM. 2000. Cutting edge: a soluble form of CTLA-4 in patients with autoimmune thyroid disease. J Immunol 164 (10):5015-5018 doi 10.4049/jimmunol.164.10.5015

Stangou M, Spartalis M, Daikidou DV, Kouloukourgiotou T, Sampani E, Lambropoulou IT, Pantzaki A, Papagianni A, Efstratiadis G. 2017. Impact of Tauh1 and Tauh2 cytokines in the progression of idiopathic nephrotic syndrome due to focal segmental glomerulosclerosis and minimal change disease. $J$ Nephropathol 6 (3):187-195 doi 10.15171/jnp.2017.32

Timoshanko JR, Kitching AR, Semple TJ, Holdsworth SR, Tipping PG. 2005. Granulocyte macrophage colonystimulating factor expression by both renal parenchymal and immune cells mediates murine crescentic glomerulonephritis. J Am Soc Nephrol 16 (9):2646-2656 doi 10.1681/ASN.2004121107

Hienz SA, Paliwal S, Ivanovski S. 2015. Mechanisms of Bone Resorption in Periodontitis. J Immunol Res 2015:615486 doi 10.1155/2015/615486

Zhao B, Han H, Zhen J, Yang X, Shang J, Xu L, Wang R. 2018. CD80 and CTLA-4 as diagnostic and prognostic

Peer] reviewing PDF | (2020:05:48577:1:2:NEW 28 Jul 2020) 
markers in adult-onset minimal change disease: a retrospective study. PeerJ 6:e5400 doi 10.7717/peerj.5400

Yu SM, Nissaisorakarn P, Husain I, Jim B. 2018. Proteinuric Kidney Diseases: A Podocyte's Slit Diaphragm and Cytoskeleton Approach. Front Med (Lausanne) 5:221 doi 10.3389/fmed.2018.00221

Funk J, Ott V, Herrmann A, Rapp W, Raab S, Riboulet W, Vandjour A, Hainaut E, Benardeau A, Singer T, Jacobsen B. 2016. Semiautomated quantitative image analysis of glomerular immunohistochemistry markers desmin, vimentin, podocin, synaptopodin and WT-1 in acute and chronic rat kidney disease models. Histochem Cell Biol 145 (3):315-326 doi 10.1007/s00418-015-1391-6

Trimarchi H. 2015. Abatacept and Glomerular Diseases: The Open Road for the Second Signal as a New Target is Settled Down. Recent Pat Endocr Metab Immune Drug Discov 9 (1):2-14 doi $10.2174 / 1872214809666150302104542$

Greenwald RJ, Freeman GJ, Sharpe AH. 2005. The B7 family revisited. Annu Rev Immunol 23:515-548 doi 10.1146/annurev.immunol.23.021704.115611 


\section{Table $\mathbf{1}$ (on next page)}

Table 1 Characteristic of patients with MCD in relapse, MCD in remission and healthy controls

Table 1 Characteristic of patients with MCD in relapse, MCD in remission and healthy controls 
Table 1. Characteristic of patients with MCD in relapse, MCD in remission and healthy controls

\begin{tabular}{|c|c|c|c|c|c|c|c|c|}
\hline $\begin{array}{l}\text { No. of } \\
\text { patients }\end{array}$ & Age & Gender & $\begin{array}{l}\text { Serum Alb } \\
(\mathrm{g} / \mathrm{l})\end{array}$ & $\begin{array}{c}\text { eGFR } \\
(\mathrm{ml} / \mathrm{min} / 1.73 \mathrm{~m} 2)\end{array}$ & Up/Uc Ratio & $\begin{array}{c}\text { Urinary CD80 } \\
\text { (ng/g Cre) }\end{array}$ & $\begin{array}{c}\text { Urinary CTLA-4 } \\
\text { (ng/g Cre) }\end{array}$ & Treatment \\
\hline \multicolumn{9}{|c|}{ MCD in relapse } \\
\hline 1 & 44 & M & 18.7 & 117.4 & 10.5 & 271.00 & 158.00 & None \\
\hline 2 & 30 & M & 29 & 108.5 & 3.7 & 737.00 & 209.00 & Pre10 mg/d \\
\hline 3 & 28 & M & 28 & 99.9 & 7 & 199.00 & 147.00 & Pre $5 \mathrm{mg} / \mathrm{d}$ \\
\hline 4 & 26 & $\mathrm{~F}$ & 24 & 131.6 & 15 & 1050.00 & 200.00 & Pre 20mg QD \\
\hline 5 & 46 & M & 26.5 & 122.9 & 3.5 & 864.00 & 157.00 & Met $12 \mathrm{mg}$ QD, Tac $1 \mathrm{mg}$ BID \\
\hline 6 & 18 & $\mathrm{~F}$ & 12.5 & 97.7 & 22.6 & 503.00 & 178.00 & Pre $15 \mathrm{mg}$ every other day \\
\hline 7 & 50 & $\mathrm{~F}$ & 25.5 & 110.8 & 11 & 560.00 & 196.00 & Met 8 mg QD \\
\hline 8 & 35 & M & 24.7 & 120.5 & 8.5 & 1250.00 & 150.00 & Pre $5 \mathrm{mg} / \mathrm{d}$ \\
\hline 9 & 22 & $\mathrm{~F}$ & 19.8 & 100.1 & 25.9 & 240.00 & 207.00 & None \\
\hline 10 & 40 & M & 23.4 & 130.8 & 18 & 310.00 & 135.00 & Pre $10 \mathrm{mg}$ every other day \\
\hline mean \pm SEM & $33.9 \pm 3.42$ & & $23.21 \pm 1.57$ & $114 \pm 3.98$ & $12.48 \pm 2.47$ & $598.4 \pm 115.8$ & $173.7 \pm 8.73$ & \\
\hline \multicolumn{9}{|c|}{$\mathrm{MCD}$ in remission } \\
\hline 11 & 28 & M & 35 & 125.9 & 0.12 & 90.00 & 142.00 & Pre $30 \mathrm{mg} / \mathrm{d}$ \\
\hline 12 & 30 & M & 40 & 138 & Neg & 79.00 & 139.00 & Pre 20 mg/d \\
\hline 13 & 45 & $\mathrm{~F}$ & 32 & 125.6 & 0.18 & 60.00 & 127.00 & Met $16 \mathrm{mg}$ QD, Tac $1 \mathrm{mg}$ BID \\
\hline 14 & 22 & M & 34 & 115 & 0.11 & 110.00 & 189.00 & Pre 60 mg/d \\
\hline 15 & 35 & $\mathrm{~F}$ & 39 & 118 & 0.06 & 120.00 & 199.00 & Met $12 \mathrm{mg} / \mathrm{d}$ \\
\hline 16 & 19 & $\mathrm{~F}$ & 40 & 140 & 0.05 & 54.00 & 165.00 & Met $12 \mathrm{mg}$ every other day \\
\hline 17 & 51 & M & 45 & 130 & 0.01 & 68.00 & 155.00 & Pre 20 mg/d \\
\hline 18 & 33 & $\mathrm{~F}$ & 47 & 99 & Neg & 73.00 & 153.00 & Pre $15 \mathrm{~g} / \mathrm{d}$ \\
\hline 19 & 29 & M & 55 & 111 & Neg & 82.00 & 126.00 & Pre 10 mg/d \\
\hline mean \pm SEM & $32.44 \pm 3.408$ & & $40.78 \pm 2.4$ & $122.5 \pm 4.386$ & $0.05 \pm 0.002$ & $81.78 \pm 7.038$ & $155 \pm 8.54$ & \\
\hline \multicolumn{9}{|c|}{ healthy controls } \\
\hline 20 & 30 & $\mathrm{~F}$ & 45 & 120 & Neg & 100.00 & 200.00 & N/A \\
\hline 21 & 22 & $\mathrm{~F}$ & 55 & 119 & Neg & 44.00 & 210.00 & N/A \\
\hline
\end{tabular}




\begin{tabular}{ccccccccc}
\hline 22 & 56 & $\mathrm{~F}$ & 50 & 110 & $\mathrm{Neg}$ & 32.00 & 168.00 & N/A \\
23 & 18 & $\mathrm{M}$ & 43 & 130 & $\mathrm{Neg}$ & 57.00 & 189.00 & N/A \\
24 & 26 & $\mathrm{~F}$ & 45 & 124 & 0.04 & 69.00 & 146.00 & N/A \\
25 & 43 & $\mathrm{M}$ & 53 & 120 & 0.02 & 75.00 & 139.00 & N/A \\
26 & 34 & $\mathrm{M}$ & 52 & 118 & 0.01 & 110.00 & 132.00 & $\mathrm{~N} / \mathrm{A}$ \\
27 & 50 & $\mathrm{~F}$ & 46 & 110 & $\mathrm{Neg}$ & 80.00 & 129.00 & $\mathrm{~N} / \mathrm{A}$ \\
28 & 44 & $\mathrm{M}$ & 44 & 112 & $\mathrm{Neg}$ & 40.00 & 127.00 & $\mathrm{~N} / \mathrm{A}$ \\
mean \pm SEM & $35.89 \pm 4.36$ & & $48.11 \pm 1.47$ & $118.1 \pm 2.214$ & $0.007 \pm 0.004$ & $67.44 \pm 8.94$ & $160 \pm 10.85$ & \\
\hline
\end{tabular}

Abbreviation: MCD, minimal change disease; eGFR, estimated glomerular filtration rate; Up/Uc, urinary protein/urinary creatinine; M, male; F, female; 2 Pre, Prednisone; Met, Methylprednisolone; Tac, Tacrolimus; Cre, Creatinine; Alb, Albumin; NA, not available 


\section{Table 2 (on next page)}

Table 2 Lymphocyte subsets in patients with MCD in relapse, MCD in remission and healthy controls

Table 2 Lymphocyte subsets in patients with MCD in relapse, MCD in remission and healthy controls 
1 Table 2. Lymphocyte subsets in patients with MCD in relapse, MCD in remission and healthy controls

\begin{tabular}{lccc}
\hline Variables & $\begin{array}{c}\text { MCD in relapse } \\
(\mathrm{n}=10)\end{array}$ & $\begin{array}{c}\text { MCD in remission } \\
(\mathrm{n}=9)\end{array}$ & $\begin{array}{c}\text { Healthy controls } \\
(\mathrm{n}=9)\end{array}$ \\
\hline $\mathrm{CD} 3+\%$ & $75.74 \pm 2.36$ & $72.59 \pm 2.15$ & $70.98 \pm 2.85$ \\
$\mathrm{CD} 3+\mathrm{CD} 4+\%$ & $35.07 \pm 2.02$ & $37.45 \pm 1.94$ & $35.23 \pm 2.4$ \\
$\mathrm{CD} 3+\mathrm{CD} 8+\%$ & $42.7 \pm 2.29^{* \#}$ & $27.42 \pm 1.51$ & $27.97 \pm 2.34$ \\
$\mathrm{CD} 4+/ \mathrm{CD} 8+$ & $0.84 \pm 0.09^{\# *}$ & $1.45 \pm 0.14$ & $1.4 \pm 0.12$ \\
$\mathrm{CD} 3-\mathrm{CD} 16^{+} / \mathrm{CD} 56^{+} \mathrm{NK} \%$ & $11.44 \pm 1.54$ & $14.44 \pm 1.4$ & $11.52 \pm 1.7$ \\
$\mathrm{CD} 3-\mathrm{CD} 19^{+} \mathrm{B}$ cells\% & $10.85 \pm 1.14$ & $15.10 \pm 2.56$ & $12.05 \pm 1.12$ \\
\hline
\end{tabular}

$2{ }^{*} \mathrm{p}<0.05$ compared MCD in relapse with healthy controls

$3{ }^{\#} \mathrm{P}<0.05$ compared $\mathrm{MCD}$ in relapse with $\mathrm{MCD}$ in remission

4 


\section{Table 3 (on next page)}

Table 3 The results of 34 human Th1-, Th2- and Th17-related cytokines in patients with $M C D$ in relapse, MCD in remission and healthy controls (median).

Table 3. The results of 34 human Th1-, Th2- and Th17-related cytokines in patients with MCD in relapse, MCD in remission and healthy controls (median). 
1 Table 3. The results of 34 human Th1-, Th2- and Th17-related cytokines in patients with MCD in relapse, MCD

2 in remission and healthy controls (median).

\begin{tabular}{|c|c|c|c|}
\hline Variables & MCD in relapse & MCD in remission & healthy controls \\
\hline CD30 & $0.05(0.02-0.07)$ & $0.07(0.04-0.07)$ & $0.07(0.03-0.29)$ \\
\hline CD40 Ligand & $0.43(0.3-0.62)$ & $0.42(0.29-0.53)$ & $0.51(0.35-0.74)$ \\
\hline $\mathrm{CD} 40$ & $0.14(0.07-0.24)^{\#}$ & $0.20(0.06-0.34)$ & $0.21(0.08-0.30)$ \\
\hline GCSF & $0.04(0.02-0.09)$ & $0.05(0.02-0.09) ※$ & $0.03(0.01-0.05)$ \\
\hline GITR (TNFRSF18) & $0.61(0.44-0.75)$ & $0.54(0.40-0.61)$ & $0.57(0.47-0.64)$ \\
\hline GM-CSF & $0.10(0.02-0.26)^{* \#}$ & $0.05(0.02-0.06)$ & $0.06(0.06-0.1)$ \\
\hline IFN-gamma & $0.54(0.44-0.65)$ & $0.52(0.49-0.56)$ & $0.49(0.41-0.57)$ \\
\hline IL-1 R1 & $0.34(0.20-0.58)$ & $0.37(0.34-0.44) ※$ & $0.23(0.13-0.32)$ \\
\hline IL-1 R2 & $0.71(0.62-0.78)$ & $0.77(0.73-0.82)$ & $0.71(0.61-0.81)$ \\
\hline IL-10 & $0.18(0.05-0.33)^{\#}$ & $0.16(0.11-0.20)$ & $0.11(0.10-0.12)$ \\
\hline IL-12 p40 & $0.68(0.60-0.76)$ & $0.62(0.61-0.64)$ & $0.70(0.61-0.64)$ \\
\hline IL-12 p70 & $0.46(0.33-0.57)$ & $0.38(0.25-0.47)$ & $0.49(0.42-0.62)$ \\
\hline IL-13 & $0.20(0.13-0.28)$ & $0.16(0.06-0.23)$ & $0.20(0.13-0.29)$ \\
\hline IL-17A & $0.16(0.10-0.25)$ & $0.16(0.07-0.21)$ & $0.18(0.14-0.26)$ \\
\hline IL-17F & $0.16(0.10-0.23)$ & $0.16(0.08-0.23)$ & $0.23(0.14-0.30)$ \\
\hline IL-17 RA & $0.03(0.01-0.05)$ & $0.04(0.03-0.06)$ & $0.03(0.03-0.06)$ \\
\hline IL-1 beta (IL-1 F2) & $0.44(0.30-0.62)$ & $0.38(0.27-0.45)$ & $0.45(0.26-0.65)$ \\
\hline IL-2 & $0.58(0.45-0.68)$ & $0.54(0.47-0.58)$ & $0.59(0.46-0.65)$ \\
\hline IL-21 & $0.54(0.41-0.66)$ & $0.52(0.48-0.57)$ & $0.50(0.40-0.58)$ \\
\hline IL-21 R & $0.49(0.35-0.67)$ & $0.49(0.44-0.54)$ & $0.41(0.34-0.50)$ \\
\hline IL-22 & $0.29(0.07-0.39)$ \# & $0.27(0.20-0.37) ※$ & $0.11(0.10-0.12)$ \\
\hline IL-23 & $0.56(0.44-0.71)$ & $0.65(0.60-0.68)$ & $0.55(0.47-0.62)$ \\
\hline IL-28A & $0.22(0.17-0.28)$ & $0.20(0.17-0.22)$ & $0.25(0.20-0.28)$ \\
\hline IL-4 & $0.21(0.13-0.30)$ & $0.16(0.08-0.22)$ & $0.23(0.08-0.22)$ \\
\hline IL-5 & $0.07(0.05-0.13)$ & $0.05(0.03-0.09) ※$ & $0.09(0.07-0.12)$ \\
\hline IL-6 & $0.08(0.04-0.11)$ & $0.07(0.05-0.11)$ & $0.08(0.06-0.12)$ \\
\hline IL-6 R & $0.95(0.89-0.98)$ & $0.94(0.88-0.98)$ & $0.96(0.93-0.99)$ \\
\hline MIP-3 $\alpha$ & $0.35(0.24-0.45)$ & $0.32(0.19-0.41)$ & $0.30(0.20-0.44)$ \\
\hline gp130 & $0.86(0.82-0.90)$ & $0.87(0.83-0.90)$ & $0.88(0.85-0.92)$ \\
\hline TGF beta 1 & $0.45(0.34-0.58)$ & $0.46(0.38-0.51)$ & $0.48(0.43-0.51)$ \\
\hline TGF beta 3 & $0.52(0.40-0.68)$ & $0.51(0.48-0.56)$ & $0.52(0.50-0.57)$ \\
\hline TNF alpha & $0.37(0.24-0.65)$ & $0.32(0.30-0.34)$ & $0.29(0.23-0.40)$ \\
\hline TNF beta & $0.45(0.30-0.64)^{\#}$ & $0.33(0.29-0.35)$ & $0.29(0.24-0.37)$ \\
\hline TRANCE (TNFSF11) & $0.22(0.13-0.36)^{*}$ & $0.15(0.07-0.20)$ & $0.18(0.12-0.21)$ \\
\hline
\end{tabular}

$3 * P<0.05$ compared relapse with remission

$4 \quad \# P<0.05$ compared relapse with healthy controls 
$5 \quad ※ P<0.05$ compared remission with healthy controls 6 


\section{Table 4 (on next page)}

Table 4 Characteristic of randomly selected patients with MCD in relapse, MCD in remission and healthy controls

Table 4. Characteristic of randomly selected patients with MCD in relapse, MCD in remission and healthy controls 
Table 4. Characteristic of randomly selected patients with MCD in relapse, MCD in remission and healthy controls

\begin{tabular}{|c|c|c|c|c|c|c|c|c|}
\hline Patient & Age & Gender & $\begin{array}{l}\text { Serum Alb } \\
(\mathrm{g} / \mathrm{l})\end{array}$ & $\begin{array}{c}\text { eGFR } \\
(\mathrm{ml} / \mathrm{min} / 1.73 \mathrm{~m} 2)\end{array}$ & Up/Uc Ratio & $\begin{array}{c}\text { Urinary CD80 } \\
\text { (ng/g Cre) }\end{array}$ & $\begin{array}{l}\text { Urinary CTLA- } \\
4 \text { (ng/g Cre) }\end{array}$ & Treatment \\
\hline \multicolumn{9}{|c|}{ MCD in relapse } \\
\hline 2 & 30 & M & 29 & 108.5 & 3.7 & 737.00 & 209.00 & Pre10 mg/d \\
\hline 4 & 26 & $\mathrm{~F}$ & 24 & 131.6 & 15 & 1050.00 & 200.00 & Pre 20mg QD \\
\hline 5 & 46 & M & 26.5 & 122.9 & 3.5 & 864.00 & 157.00 & Met $12 \mathrm{mg}$ QD, Tac $1 \mathrm{mg}$ BID \\
\hline 6 & 18 & $\mathrm{~F}$ & 12.5 & 97.7 & 22.6 & 503.00 & 178.00 & Pre $15 \mathrm{mg}$ every other day \\
\hline 7 & 50 & $\mathrm{~F}$ & 25.5 & 110.8 & 11 & 560.00 & 196.00 & Met 8 mg QD \\
\hline 10 & 40 & M & 23.4 & 130.8 & 18 & 310.00 & 135.00 & Pre $10 \mathrm{mg}$ every other day \\
\hline mean \pm SEM & $35 \pm 5.05$ & & $23.48 \pm 2.34$ & $117 \pm 5.54$ & $12.3 \pm 3.15$ & $670.7 \pm 109$ & $179.2 \pm 11.6$ & \\
\hline \multicolumn{9}{|c|}{ MCD in remission } \\
\hline 14 & 22 & M & 34 & 115 & 0.11 & 110.00 & 189.00 & Pre $60 \mathrm{mg} / \mathrm{d}$ \\
\hline 15 & 35 & $\mathrm{~F}$ & 39 & 118 & 0.06 & 120.00 & 199.00 & Met $12 \mathrm{mg} / \mathrm{d}$ \\
\hline 19 & 29 & M & 55 & 111 & Neg & 82.00 & 126.00 & Pre $10 \mathrm{mg} / \mathrm{d}$ \\
\hline mean \pm SEM & $28.67 \pm 3.75$ & & $42.67 \pm 6.33$ & $114.7 \pm 2.02$ & $0.06 \pm 0.03$ & $104 \pm 11.37$ & $171.3 \pm 22.85$ & \\
\hline \multicolumn{9}{|c|}{ healthy controls } \\
\hline 22 & 56 & $\mathrm{~F}$ & 50 & 110 & $\mathrm{Neg}$ & 32.00 & 168.00 & N/A \\
\hline 26 & 34 & $\mathrm{M}$ & 52 & 118 & 0.01 & 110.00 & 132.00 & N/A \\
\hline 28 & 44 & M & 44 & 112 & Neg & 40.00 & 127.00 & N/A \\
\hline mean \pm SEM & $44 \pm 6.36$ & & $48.67 \pm 2.4$ & $113.3 \pm 2.4$ & $0.003 \pm 0.003$ & $60.67 \pm 24.77$ & $142.3 \pm 12.91$ & \\
\hline
\end{tabular}

2 Abbreviation: MCD, minimal change disease; eGFR, estimated glomerular filtration rate; Up/Uc, urinary protein/urinary creatinine; M, male; F, female;

3 Pre, Prednisone; Met, Methylprednisolone; Tac, Tacrolimus; Cre, Creatinine; Alb, Albumin; NA, not available 


\section{Figure 1}

Figure 1 Cytokine profiles of patients with MCD and normal control.

Figure 1 Cytokine profiles of patients with MCD and normal control. Cytokine Ab array images from a patient with MCD in relapse $(A)$, a patient in remission (B), and a healthy control (C) were shown. The levels of cytokine in serum were represented by the spot density. The four spots in the upper left and two in the lower right corners of the membranes indicate positive controls. The position of 34 human Th1-, Th2- and Th17--related cytokines in the antibody based microarray (D). 


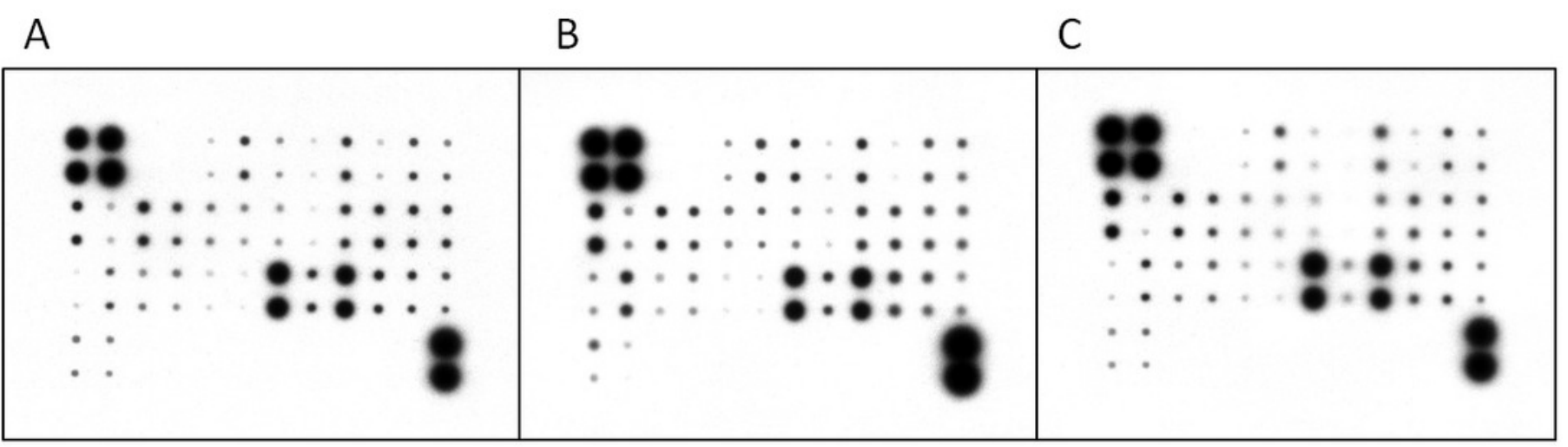

D

\begin{tabular}{|c|c|c|c|c|c|c|c|c|c|c|c|c|}
\hline & A & $B$ & $C$ & $\mathrm{D}$ & $E$ & $F$ & G & $\mathrm{H}$ & I & $\mathrm{J}$ & $\mathrm{K}$ & L \\
\hline 1 & POS1 & POS2 & POS3 & NEG & NEG & CD30 & $\begin{array}{l}\text { CD40 } \\
\text { Ligand }\end{array}$ & CD40 & G-CSF & GITR & GM-CSF & $\begin{array}{l}\text { IFN- } \\
\text { gamma }\end{array}$ \\
\hline 2 & POS1 & POS2 & POS3 & NEG & NEG & CD30 & $\begin{array}{l}\text { CD40 } \\
\text { Ligand }\end{array}$ & CD40 & G-CSF & GITR & GM-CSF & $\begin{array}{l}\text { IFN- } \\
\text { gamma }\end{array}$ \\
\hline 3 & IL-1 sRI & $\begin{array}{l}\text { IL-1 } \\
\text { sRII }\end{array}$ & IL-10 & $\begin{array}{l}\text { IL-12 } \\
\text { p40 }\end{array}$ & $\begin{array}{l}\text { IL-12 } \\
\text { p70 }\end{array}$ & IL-13 & IL-17A & IL-17F & IL-17R & IL-1 $\beta$ & IL-2 & IL-21 \\
\hline 4 & IL-1 sRI & $\begin{array}{l}\text { IL-1 } \\
\text { sRII }\end{array}$ & IL-10 & $\begin{array}{l}\text { IL-12 } \\
\text { p40 }\end{array}$ & $\begin{array}{l}\text { IL-12 } \\
\text { p70 }\end{array}$ & IL-13 & IL-17A & IL-17F & IL-17R & IL-1 $\beta$ & IL-2 & IL-21 \\
\hline 5 & IL-21R & IL-22 & $\begin{array}{l}\text { IL-23 } \\
\text { p19 }\end{array}$ & $\begin{array}{l}\text { IL- } \\
28 A\end{array}$ & IL-4 & IL-5 & IL-6 & IL-6 sR & MIP-3a & sgp130 & TGF- $\beta 1$ & TGF- $\beta 3$ \\
\hline 6 & IL-21R & IL-22 & $\begin{array}{l}\text { IL-23 } \\
\text { p19 }\end{array}$ & $\begin{array}{l}\text { IL- } \\
28 A\end{array}$ & IL-4 & IL-5 & IL-6 & IL-6 sR & MIP-3a & sgp130 & TGF- $\beta 1$ & TGF- $\beta 3$ \\
\hline 7 & TNF- $a$ & TNF- $\beta$ & TRANCE & NEG & NEG & NEG & NEG & NEG & NEG & NEG & NEG & NEG \\
\hline 8 & TNF- $a$ & TNF- $\beta$ & TRANCE & NEG & NEG & NEG & NEG & NEG & NEG & NEG & NEG & NEG \\
\hline
\end{tabular}




\section{Figure 2}

Figure $2 \mathrm{CD} 80$ urinary concentrations (ng/g creatinine) in patients with MCD and healthy controls

Figure 2 CD80 urinary concentrations (ng/g creatinine) in patients with MCD in relapse, $M C D$ in remission and healthy controls. $(A)$ comparisons: $P<0.001 M C D$ in relapse vs $M C D$ in remission; $P<0.001$ MCD in relapse vs healthy controls; (B) Correlation between urinary CD80 and proteinuria in patients with $M C D$ in relapse. (C) Urinary excretion of CTLA-4 (ng/g creatinine) in patients with MCD and control subjects. (D) Correlation between urinary CTLA-4 and proteinuria in MCD patients in relapse. (E) Correlation between urinary CD80 and urinary CTLA-4 in MCD patients in relapse. (F). Correlation between urinary CD80 and urinary CTLA-4 in MCD patients in remission. 


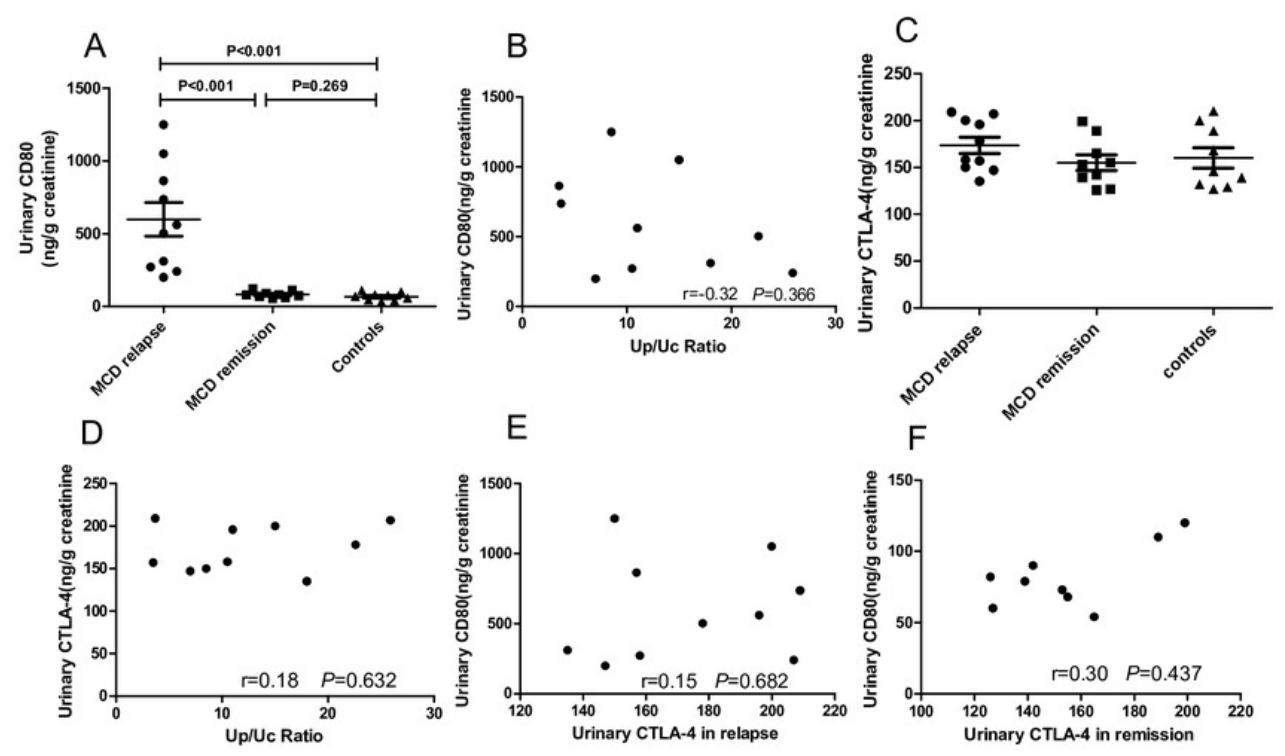




\section{Figure 3}

Figure 3 CD80 and CTLA-4 in patients with MCD in relapse, MCD in remission and healthy controls.

Figure 3 CD80 and CTLA-4 in patients with MCD in relapse, MCD in remission and healthy controls. (A) The ratio of CD80 ( $\mathrm{ng} / \mathrm{g}$ creatinine) to CTLA-4 ( $\mathrm{ng} / \mathrm{g}$ creatinine) in urine in patients with MCD in relapse, MCD in remission and healthy controls. (B) Serum CD80/CTLA-4 ratio between patients with MCD in relapse, MCD in remission and healthy controls. (C) Serum CTLA-4 concentrations in patients with MCD in relapse, MCD in remission and healthy controls. 

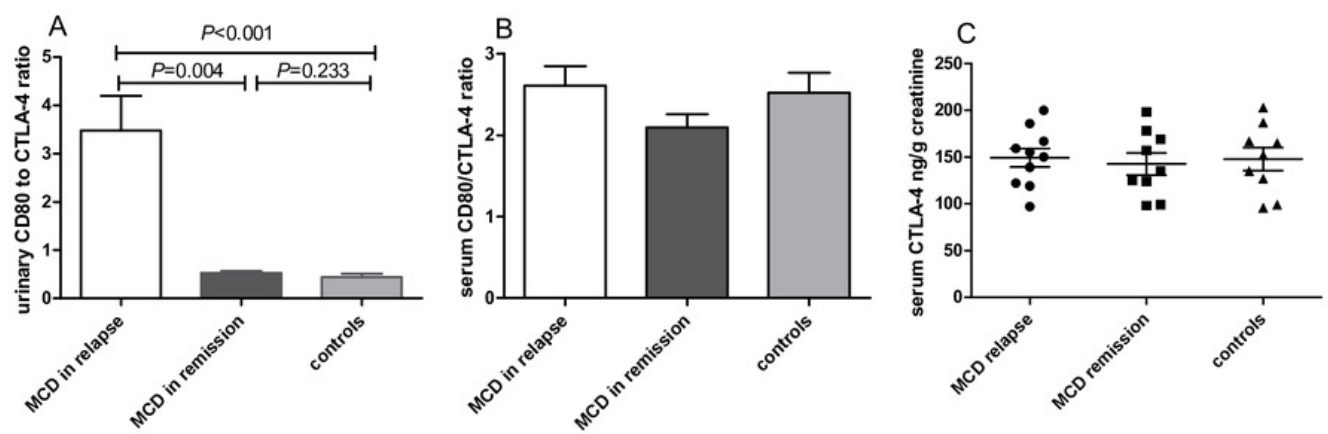
Figure 4

Figure 4 The expression of CD80 in glomeruli of MCD patient in relapse.

Figure 4 The expression of CD80 in glomeruli of MCD patient in relapse. CD80 is expressed (green stain) in the glomeruli of MCD patient in relapse (A and D). Synaptopodin is expressed (red stain) in glomeruli of MCD patients in relapse (B). WT-1 is expressed (red stain) in glomeruli of MCD patients in relapse (E). CD80 and synaptopodin colocalized at the glomeruli (C). CD80 and WT-1 co-localized at the glomeruli (F). 

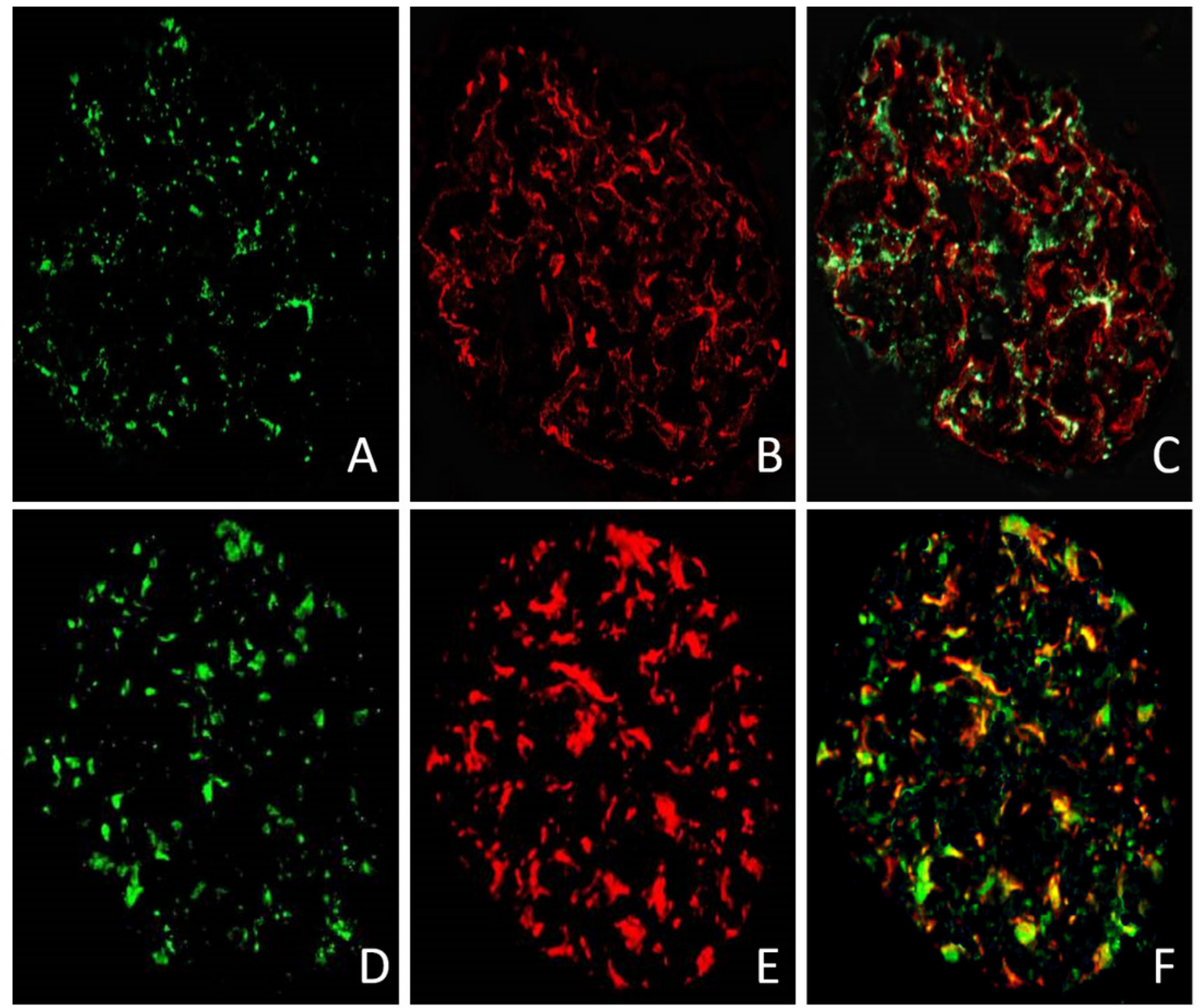